\title{
The Effects of Cognitive Learning and Imagination Training on the Balances of the 14-16 Years Old Handball Players
}

\author{
Mehmet Behzat Turan ${ }^{1}$, Osman Diş̧̧eken ${ }^{2}$ \\ ${ }^{1}$ Erciyes University Physical Education and Sport Department, Kayseri, Turkey \\ ${ }^{2}$ Hacı Bektasi Veli University Physical Education and Sport Department, Nevşehir, Turkey \\ Correspondence: Mehmet Behzat TURAN, Erciyes University Physical Education and Sport Department, 38039, \\ Kayseri, Turkey.
}

Received:April 9, 2018

doi:10.11114/jets.v7i1.3834
Online Published: December 4, 2018

URL: https://doi.org/10.11114/jets.v7i1.3834

\begin{abstract}
The purpose of this research is to examine the effects of imagination and cognitive learning exercises, which are applied to increase the success of elite handball players, on their balance skills.

The research group consists of a total of 36 voluntary male athletes, 18 of which are the control group and 18 of them are the experimental group, aged between 14 and 16, with at least 5 years of sports experience, who have been playing handball in Kayseri Youth Sports Club. For the study group, 8-day, 30-minute cognitive training and imagination study program was applied as two sets per day. No exercise was applied to the control group. Static and dynamic balance tests were applied to all of the participants (study and control group at the beginning and end of the study. According to the results of the analysis performed at the end of the study, a significant difference was found between the post-test results of all balance parameters of the experimental and control groups $(\mathrm{p}<0.05)$. When the pre-test and post-test results of the control group were compared, there was a significant difference between the scores of Static, Level8, Level4 and Oscillation CE ( $\mathrm{p}<0.05)$ and there was no significant difference between Level2 and Oscillation OE $(\mathrm{p}>0.05)$. When the pre-test and post-test results of the experimental group were compared, a significant difference was found between all equilibrium parameters $(\mathrm{p}<0.05)$.
\end{abstract}

As the result, it was found that cognitive imagination programs have positive effects on learning the balance skills in handball players under the light of the obtained findings.

Keywords: handball, imagination, cognitive learning, balance

\section{Introduction and Purpose}

Handball is a circuitous sport aiming at responding the opponent's offence with the best defence, trying to prevent the opponent from scoring, and scoring on the offence; and it contains numerous movements. The technical-tactical, conditional-mental and psychological properties, as a whole, constitute the basis of the performance in handball. The balance skill that forms the basis of performance and is at the centre of conditional skills is known to have a significant role in the successful display of many sports skills, in changing direction, standing, starting, holding, moving an object and protecting the position of the body. According to Meinel and Schnabel, balance is defined as keeping the whole body stable and protecting the status of the body during and after a movement (Altay, 2001). The individual's ability to protect the balance can be defined as a decisive factor in the development of other motor systems (Erkmen, 2007). Balance control is a complex motor skill that involves the integration of sensory inputs as well as the planning and execution of flexible types of motion. There are two types of balance: static and dynamic balance. The ability to provide the balance of the body in a specific place or position is called static balance (Hazar \& Tasmektepligil, 2008). The dynamic balance is the result of neutralizing the external forces acting on the body by the muscles and soft tissues around the joints (Nichols et al., 1995).

In handball, technical-tactical, conditional-mental and psychological properties all constitute the basis of the performance. Everyone in sporting activities faces both physical and mental loads. To minimize the impact of these loads, training is carried out against the factors that cause these loads. However, during training, weight is often given to fitness exercises, and technical and tactical training (İkizler, 1997). Mental training is among the things that an athlete must learn and practice in his/her annual training program (Karagözoğlu, 2005). 
Imagination is an experience similar to the sensory ones such as seeing, feeling and hearing, but generally occurring in the absence of an external stimulus. For example, a handball player can imagine the voice of a handball, touching it, and even though the audience and friends' screams that do not actually exist. These experiences are, in general, the products of our memory. These experiences can be remembered internally in a clear way and can be built on old external events (Konter, 2006).

The sporting world has always focused on the highest performance concept. For this reason, the athlete who aims to achieve high performance must be prepared for the competition psychologically as well as physiologically. This preparation phase of imagination training and cognitive-based learning techniques are very important contributors to the high performance of an athlete.

According to cognitive theorists, learning is defined as the individual's perception of an external stimulus, comparison of previous knowledge, the creation of new knowledge, and memorization and remembering of obtained information (Erdem, 1998). One of the most important theories in the cognitive approach is that the individual takes the knowledge and processes it according to his or her own self (Özden, 2004). Knowledge passes through four processes. These are sensory recording, short-term memory, long-term memory and control processes. In sensory memory, the surrounding stimuli are taken by sensory organs and transmitted to the short-term memory, in other words, to the working memory. With brief repetitions, the information is sent to the long-term memory to be coded and stored. When this information is needed, the information is called up from the long-term memory and processed in short-term memory (Ataman, 2004).

The purpose of this research is to demonstrate the effects of cognitive-based learning and imagination skills on learning and on the ability of balance, which is a techno-motoric feature for sportsmen, in athletes.

\section{Material and Method}

A total of 36 male volunteers between the ages of 14 and 16, handball licensed for at least 5 years, 18 of which were experimental and 18 were control groups participated in the study. The groups were defined in a randomized way. Athletes have been selected from persons who have not experienced any limb anomaly within the last 6 months (this was determined by asking the athletes themselves on the information form).

\section{Study Protocol (Method)}

The study was carried out in Erciyes University School of Physical Education and Sports laboratories. This study was conducted in two stages (pre-test and post-test). First, the age, height (m), weight (kg) and body mass indexes (BMI: kg $/ \mathrm{m} 2$ ) of the volunteers were taken 1 day before starting the training. Afterwards, the athletes' static balance, Dynamic Level8, Dynamic Level4, Dynamic Level2, Oscillation Index eye-open (OE) and Oscillation Index eye-closed (CE) balance values were measured through pre-tests. The same day, athletes were given information about the study. Then, imagination and cognitive learning and balance training were applied only to the experimental group, with no other applications, including 8 days, 40 minutes, 2 periods per day.

At the end of the eighth day, as test results, static equilibrium, Dynamic Level8, Dynamic Level4, Dynamic Level2, Oscillation Index OE and Oscillation Index CE balance tests were performed on the experimental and control groups.

\section{Data Collection Tools:}

\section{Height, Weight and BMI Measurements:}

The heights of the athletes were measured by the height measurement scale $(0.1 \mathrm{~cm}$ accuracy), with bare feet or socks, and the body weights were measured with a scale $(0.1 \mathrm{~kg}$ accuracy) while the athletes were wearing shorts. Body mass indexes were determined by dividing the body weights by the square of the heights (Zorba \& Ziyagil, 1995; Tamer, 2000).

\section{Balance Device and Balance Measurements:}

In this study, Biodex Balance System (Biodex, Inc., Shirley, New York) was used for static and dynamic balance measurements.

The Biodex balance device consists of a mobile platform that allows the participant to stand still and move forward, backward and sideways. The platform has a mobility rating of $0-12.12$ is the most stable, 0 is the most mobile platform (Figure 1). In this study, Level8, Level4 and Level2 grades are used for dynamic measurements. Participants were taken to the tests after they had warmed up and stretched for 5 minutes with their sports clothes. The static balance test was performed with the eyes open and the eyes closed, respectively, in the double leg standing position. The dynamic balance test was applied at the double leg standing position. After the subjects had been exercised on the balance platform for about 2-3 minutes, the tests were started and a rest was given for about 1 minute between the test series. During static tests, subjects were requested not to get any support using their arms. With this position, it was planned that the chances of the person to misjudge the test by touching the support rail and the effect of the arms on the balance to de decreased. During the test, the subjects were informed that the upper body movements had to be lowered to the minimum and that only the legs had to be 
used to complete the test. If, during the measurement period, it was observed that the balance could not be maintained, or here were environmental factors or touching with the hand or foot, the measurement was cancelled and the test was repeated.

\section{Static Balance Measurements:}

The static test was performed on the fixed platform, with the eyes open and the eyes closed in the position of standing on the double leg. The optimal position in the double leg test is that the feet are open at the shoulder width. The standing positions of the feet are determined to be equidistant from the origin point, with reference to the lines on the $\mathrm{x}$ and $y$ axis of the platform shown in Figure 1. During the test, which lasted for a total of 30 seconds, the position was asked to be protected and the subject's position was monitored from the screen.

\section{Dynamic Balance Measurements:}

The dynamic test was performed in the double leg position. The optimal position is that the feet are open at shoulder width, as in the static test. The standing positions of the feet are determined to be equidistant from the origin point, with reference to the lines on the $\mathrm{x}$ and $\mathrm{y}$ axis. The pressure level of the Stabilometer is adjusted for the difficulty levels Level8, Level4 and Level2 (12 levels, the most difficult level 0) for these tests. The platform was completed within 30 seconds by following the circular route on the screen. The maximum performance of the individual who failed the test at the current time limit was recorded as the test result.

\section{Postural Body Oscillation Measurements:}

Posture is basically the body status that is provided by stretching (myotatic) reflex and is protected against gravity. Posture and balance are provided by the stimulation from the vestibular organs found in the receptor and inner ear through reflexes (Günay \& Cicioğlu, 2001). The body oscillation was performed with the eyes open and the eyes closed, on the fixed platform in the position of standing on the double leg. The optimal position for the double leg test is that the feet are open at the shoulder width. The standing positions of the feet were determined to be equidistant from the origin point, with reference to the lines on the $\mathrm{x}$ and $\mathrm{y}$ axis of the platform. During the entire 30 -second test period, volunteers were asked to protect their position with the eyes open and closed.

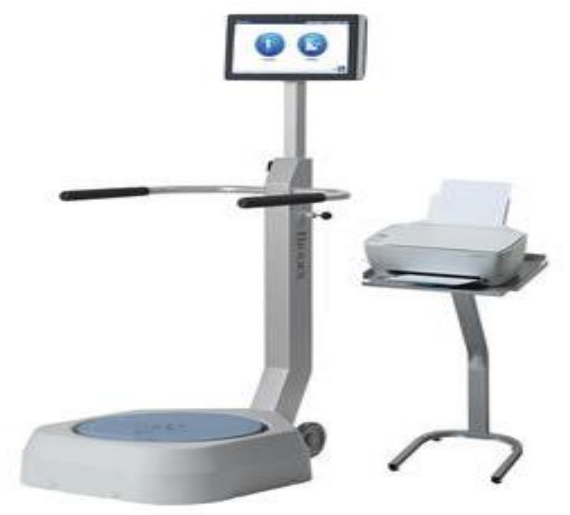

Figure 1. Biodex Balance System

Mental Training Protocol: Video-assisted mental training (Aktepe, 2006, Kolayiş, 2002) model was applied to the subjects for 8 consecutive days with an accelerating cognitive approach to learning. For the development of the visualization skills of volunteers, mental preparation techniques were applied in the first week before the mental training (Syer \& Connolly, 1988). Afterwards, input exercises were carried out and studies were performed to visualize the balance skill by all the senses in the mind.

8 days long cognitive based, imaginative and video-assisted balance skill study program.

\begin{tabular}{lll}
\hline & \multicolumn{1}{c}{ First 30 min. } & Monday \\
\hline 1. Week & Spatial oscillation, Balance and G point & Conditions Affecting Balance, Balance Classification \\
2. Week & Static balance, Group work & Imagination and balance, Video analysis \\
3. Week & Introduction of Balance device, Imagination & Quiet environment exercise, group work \\
4. Week & Static imagination, Quiet environment exercises & Dynamic imagination, Video analysis \\
5. Week & Body oscillation imagination, Video analysis & Dynamic imagination, Video analysis \\
6. Week & Body oscillation imagination & Open and closed eye imagination, Video analysis \\
7. Week & Balance (object) device imagination & Quiet environment imagination and group work \\
8. Week & Balance in other branches, Group work & Video analysis, Imagination and balance \\
\hline
\end{tabular}




\section{Data Analysis}

The data obtained after the study were evaluated in the SPSS 20 program. First, descriptive statistics are presented. The number of participants in the study group is below 50 subjects. For this reason, whether the data shows a normal distribution was determined by examining the Shapiro-Wilk test, the histogram, Q-Q, P-P graphs with skewness and kurtosis values. Paired Samples T-test was used for intra-group measurements and Independent Samples T-test was used for inter-group measurements since the data showed normal distribution. Significance level was accepted as $\mathrm{p}<0.05$.

\section{Findings}

Table 1. Descriptive Statistics of Participants

\begin{tabular}{|c|c|c|c|c|c|c|c|c|c|}
\hline & \multicolumn{5}{|c|}{ Pre-test } & \multicolumn{4}{|c|}{ Post-test } \\
\hline \multirow{7}{*}{$\begin{array}{l}\text { Control } \\
\text { Group }\end{array}$} & & $\mathrm{N}$ & Min & Max & $\overline{\mathrm{x}} \pm \mathrm{SS}$ & $\mathrm{N}$ & Min & $\operatorname{Max}$ & $\overline{\mathrm{x}} \pm \mathrm{SS}$ \\
\hline & Static & 18 & .60 & 2.20 & $1.17 \pm .45$ & 18 & .49 & 2.12 & $1.11 \pm .47$ \\
\hline & Level8 & 18 & 1.01 & 2.60 & $1.75 \pm .36$ & 18 & .92 & 2.42 & $1.64 \pm .37$ \\
\hline & Level4 & 18 & 1.40 & 2.43 & $1.95 \pm .38$ & 18 & 1.33 & 2.40 & $1.83 \pm .37$ \\
\hline & Level2 & 18 & 1.89 & 3.45 & $2.82 \pm .48$ & 18 & 1.67 & 3.72 & $2.75 \pm .61$ \\
\hline & Oscillation OE & 18 & .74 & 1.13 & $1.06 \pm .11$ & 18 & .75 & 1.21 & $.98 \pm .13$ \\
\hline & Oscillation CE & 18 & 1.12 & 2.66 & $1.69 \pm .36$ & 18 & .99 & 2.63 & $1.60 \pm .27$ \\
\hline \multirow{6}{*}{$\begin{array}{l}\text { Experimental } \\
\text { Group }\end{array}$} & Static & 18 & .3 & 2.0 & $0.98 \pm .50$ & 18 & .2 & 1.7 & $0.73 \pm .40$ \\
\hline & Level8 & 18 & .8 & 2.4 & $1.54 \pm .44$ & 18 & .9 & 1.9 & $1.27 \pm .28$ \\
\hline & Level4 & 18 & 1.1 & 2.4 & $1.73 \pm .42$ & 18 & .8 & 2.1 & $1.41 \pm .40$ \\
\hline & Level2 & 18 & 1.1 & 3.8 & $2.44 \pm .94$ & 18 & .7 & 3.5 & $2.12 \pm .95$ \\
\hline & Oscillation OE & 18 & .62 & 1.40 & $0.92 \pm .20$ & 18 & .42 & 1.00 & $0.69 \pm .18$ \\
\hline & Oscillation CE & 18 & .89 & 2.66 & $1.46 \pm .44$ & 18 & .45 & 1.92 & $1.17 \pm .32$ \\
\hline
\end{tabular}

In Table 1, when the descriptive pretest-posttest statistics of the volunteers were examined, the Control Group pre-test results were $1.17 \pm 0.45$ for Static, $1.75 \pm .36$ for Level8, $1.95 \pm .38$ for Level4, $2.82 \pm .48$ for Level2, $1.06 \pm .11$ for Oscillation OE, and $1.69 \pm .36$ for Oscillation CE, while Control Group post-test results were $1.11 \pm 0.47$ for Static, $1.64 \pm .37$ for Level8, $1.83 \pm .37$ for Level4, $2.75 \pm .61$ for Level2, $.98 \pm 13$ for Oscillation OE and $1.60 \pm 27$ for Oscillation CE, in 18 athletes participated. When we examined the descriptive pre-test and post-test statistic of the test group volunteers, the Experimental Group pre-test results were $0.98 \pm .50$ for Static, $1.54 \pm .44$ for Level8, $1.73 \pm .42$ for Level4, $2.44 \pm .94$ for Level2, $0.92 \pm 0.20$ for Oscillation OE, and 1.46 \pm .44 for Oscillation CE, while Control Group post-test results were $0.73 \pm .40$ for Static, $1.27 \pm .28$ for Level8, 1.41 \pm .40 for Level4, $2.12 \pm .95$ for Level2, $0.69 \pm .18$ for Oscillation $\mathrm{OE}$ and $1.17 \pm .32$ for Oscillation CE, in 18 athletes participated.

Table 2. Control and Experimental Group Pre-Test Comparison

\begin{tabular}{|c|c|c|c|c|c|}
\hline & Group & $\mathrm{N}$ & $\overline{\mathrm{x}} \pm \mathrm{SS}$ & $\mathrm{t}$ & $\mathrm{p}$ \\
\hline \multirow{2}{*}{ Static } & Control & 18 & $1.17 \pm .45$ & \multirow{2}{*}{1.119} & \multirow{2}{*}{.239} \\
\hline & Experimental & 18 & $0.98 \pm .50$ & & \\
\hline \multirow{2}{*}{ Level8 } & Control & 18 & $1.75 \pm .36$ & \multirow{2}{*}{1.575} & \multirow{2}{*}{.125} \\
\hline & Experimental & 18 & $1.54 \pm .44$ & & \\
\hline \multirow{2}{*}{ Level4 } & Control & 18 & $1.95 \pm .38$ & \multirow{2}{*}{1.595} & \multirow{2}{*}{.120} \\
\hline & Experimental & 18 & $1.73 \pm .42$ & & \\
\hline \multirow{2}{*}{ Level2 } & Control & 18 & $2.82 \pm .48$ & \multirow{2}{*}{1.517} & \multirow{2}{*}{.142} \\
\hline & Experimental & 18 & $2.44 \pm .94$ & & \\
\hline \multirow{2}{*}{ Oscillation $\mathrm{OE}$} & Control & 18 & $1.06 \pm .11$ & \multirow{2}{*}{1.676} & \multirow{2}{*}{.103} \\
\hline & Experimental & 18 & $0.92 \pm .20$ & & \\
\hline \multirow{2}{*}{ Oscillation CE } & Control & 18 & $1.69 \pm .36$ & \multirow{2}{*}{1.767} & \multirow{2}{*}{.086} \\
\hline & Experimental & 18 & $1.46 \pm .44$ & & \\
\hline
\end{tabular}

In Table 2, no significant difference was found between Static, Level8, Level4, Level2, Oscillation OE, and Oscillation CE scores when Control and Experiment Group pre-test results were compared ( $p>0.05)$.

Table 3. Control and Experimental Group Post-Test Comparison

\begin{tabular}{|c|c|c|c|c|c|}
\hline Balance & Group & $\mathrm{N}$ & $\overline{\mathrm{x}} \pm \mathrm{SS}$ & $\mathrm{t}$ & $\mathrm{p}$ \\
\hline \multirow{2}{*}{ Static } & Control & 18 & $1.11 \pm .47$ & \multirow[b]{2}{*}{2.541} & \multirow{2}{*}{$.016^{*}$} \\
\hline & Experimental & 18 & $0.73 \pm .40$ & & \\
\hline \multirow{2}{*}{ Level8 } & Control & 18 & $1.64 \pm .37$ & \multirow{2}{*}{3.420} & \multirow[b]{2}{*}{$.002 * *$} \\
\hline & Experimental & 18 & $1.27 \pm .28$ & & \\
\hline \multirow{2}{*}{ Level4 } & Control & 18 & $1.83 \pm .37$ & \multirow{2}{*}{3.273} & \multirow{2}{*}{$.002 * *$} \\
\hline & Experimental & 18 & $1.41 \pm .40$ & & \\
\hline \multirow{2}{*}{ Level2 } & Control & 18 & $2.75 \pm .61$ & \multirow{2}{*}{-4.806} & \multirow{2}{*}{$.000 * *$} \\
\hline & Experimental & 18 & $2.12 \pm .95$ & & \\
\hline Oscillation & Control & 18 & $0.98 \pm .13$ & \multirow{2}{*}{5.707} & \multirow{2}{*}{$.000 * *$} \\
\hline $\mathrm{OE}$ & Experimental & 18 & $0.69 \pm .18$ & & \\
\hline Oscillation & Control & 18 & $1.60 \pm .27$ & \multirow{2}{*}{3.701} & \multirow[t]{2}{*}{$.001 * *$} \\
\hline $\mathrm{CE}$ & Experimental & 18 & $1.17 \pm .32$ & & \\
\hline
\end{tabular}


In Table 3, a significant difference was found between Static, Level8, Level4, Level2, Oscillation OE, and Oscillation CE scores when Control and Experimental Group post-test results were compared $(\mathrm{p}<0.05)$.

Table 4 Control Group Pretest-Posttest Comparison

\begin{tabular}{|c|c|c|c|c|c|c|}
\hline Balance & Group & $\mathrm{N}$ & $\overline{\mathrm{x}} \pm \mathrm{SS}$ & Correlation & $\mathrm{t}$ & $p$ \\
\hline Static & $\begin{array}{c}\text { Pre-test } \\
\text { Post-test }\end{array}$ & $\begin{array}{l}18 \\
18\end{array}$ & $\begin{array}{l}1.17 \pm .45 \\
111+47\end{array}$ & $\begin{array}{l}.987 \\
000\end{array}$ & 3.555 & $.002 *$ \\
\hline Level8 & $\begin{array}{l}\text { Pre-test } \\
\text { Post-test }\end{array}$ & $\begin{array}{l}18 \\
18\end{array}$ & $\begin{array}{l}1.75 \pm .36 \\
1.64 \pm .37\end{array}$ & $\begin{array}{l}.087 \\
.000\end{array}$ & 7.755 & $.000 * *$ \\
\hline Level4 & $\begin{array}{l}\text { Pre-test } \\
\text { Post-test }\end{array}$ & $\begin{array}{l}18 \\
18\end{array}$ & $\begin{array}{l}1.95 \pm .38 \\
1.83 \pm .37\end{array}$ & $\begin{array}{l}.972 \\
.000\end{array}$ & 5.466 & $.000 * *$ \\
\hline Level2 & $\begin{array}{c}\text { Pre-test } \\
\text { Post-test }\end{array}$ & $\begin{array}{l}18 \\
18\end{array}$ & $\begin{array}{l}2.82 \pm .48 \\
2.75 \pm .61\end{array}$ & $\begin{array}{l}.910 \\
.000\end{array}$ & 1.137 & .272 \\
\hline Oscillation $\mathrm{OE}$ & $\begin{array}{c}\text { Pre-test } \\
\text { Post-test }\end{array}$ & $\begin{array}{l}18 \\
18 \\
\end{array}$ & $\begin{array}{l}1.06 \pm .11 \\
0.98 \pm .13 \\
\end{array}$ & $\begin{array}{l}.689 \\
.000 \\
\end{array}$ & 1.137 & .279 \\
\hline Oscillation CE & $\begin{array}{c}\text { Pre-test } \\
\text { Post-test }\end{array}$ & $\begin{array}{l}18 \\
18\end{array}$ & $\begin{array}{l}1.69 \pm .36 \\
1.60 \pm .27\end{array}$ & $\begin{array}{l}.982 \\
.000 \\
\end{array}$ & 5.991 & $.000 * *$ \\
\hline
\end{tabular}

In Table 4, no significant difference was found between Level 2 and Oscillation OE scores (p>0.05), while a significant difference was found between Static, Level8, Level4 and Oscillation CE scores ( $p<0.05)$ when Control Group pretest-posttest results were compared

Table 5. Experimental Group Pretest-Posttest Comparison

\begin{tabular}{|c|c|c|c|c|c|c|}
\hline Balance & Group & $\mathrm{N}$ & $\mathrm{X} \pm \mathrm{SS}$ & Correlation & $\mathrm{t}$ & $\mathrm{p}$ \\
\hline \multirow{2}{*}{ Static } & Pre-test & 18 & $0.98 \pm .50$ & .974 & \multirow{2}{*}{7.291} & \multirow{2}{*}{$.000 * *$} \\
\hline & Post-test & 18 & $0.73 \pm .40$ & .000 & & \\
\hline \multirow{2}{*}{ Level8 } & Pre-test & 18 & $1.54 \pm .44$ & .832 & \multirow{2}{*}{4.429} & \multirow{2}{*}{$.000^{* *}$} \\
\hline & Post-test & 18 & $1.27 \pm .28$ & .004 & & \\
\hline \multirow{2}{*}{ Level4 } & Pre-test & 18 & $1.73 \pm .42$ & .968 & \multirow{2}{*}{12.894} & \multirow{2}{*}{$.000 * *$} \\
\hline & Post-test & 18 & $1.41 \pm .40$ & .000 & & \\
\hline \multirow{2}{*}{ Level2 } & Pre-test & 18 & $2.44 \pm .94$ & .992 & \multirow{2}{*}{11.800} & \multirow{2}{*}{$.000^{* *}$} \\
\hline & Post-test & 18 & $2.12 \pm .95$ & .000 & & \\
\hline \multirow{2}{*}{ Oscillation OE } & Pre-test & 18 & $0.92 \pm .20$ & .746 & \multirow{2}{*}{7.101} & \multirow{2}{*}{$.000 * *$} \\
\hline & Post-test & 18 & $0.69 \pm .18$ & .000 & & \\
\hline \multirow{2}{*}{ Oscillation CE } & Pre-test & 18 & $1.46 \pm .44$ & .904 & \multirow{2}{*}{5.937} & \multirow{2}{*}{$.000 * *$} \\
\hline & Post-test & 18 & $1.17 \pm .32$ & .000 & & \\
\hline
\end{tabular}

$\mathrm{p}<0.005^{*} \cdot \mathrm{p}<0.001^{* *}$

In Table 5, a significant difference was found between Static, Level8, Level4, Level2, Oscillation OE, and Oscillation $\mathrm{CE}$ scores when Control and Experimental Group pretest-posttest results were compared $(\mathrm{p}<0.05)$.

\section{Discussion and Results}

Mental training is used extensively in studying the sports skills. With the imagination in the positive direction, the skills can be improved, and these skills can be demonstrated more successfully and strongly by correcting their weaknesses. Mental training is a psychological skill and has an important power to improve the performance of the athlete (Konter, 1999, Altıntaş \& Akalan, 2008). Cognitive learning, in this sense, supports imagination (mental). The processes of receiving, understanding and analyzing the information begin to be revived in their minds and are reflected in the outward direction in time as well. In fact, the change in behaviour in cognitive learning, which is fully occurring in the mind, is also reflected in the outside appearance.

In our study, no statistically significant difference was found between the static and dynamic balance pre-test results of the experimental and control groups $(\mathrm{P}>0.05)$. This shows that the study group was homogeneously distributed.

When we examined the static and dynamic balance post-test data of the experimental and control groups, a significant difference was found in all parameters $(\mathrm{P}<0.05)$. This difference is thought to be related to imagination and cognitive balance studies in the experimental group for 8 days. Mental training is a psychological skill and has an important power to improve the performance of the athlete (Konter, 1999). Furthermore, it is known that mental training and cognitive-based teaching methods, which are among the learning-accelerating practices, increase the learning of the athletes' skills (May,1986; Mahoney, \& Sunin, 1986).

In his work, Sosovec examined the effects of visual imagination on the penalty shootout in the football and divided the subjects into mental, physical, and mental and physical training groups. It was determined that, for both of the physical and mental training groups, the rates of the shots on target was higher than the other two groups (Sosovec, 2004).

A statistically significant difference was found between Static, Level8, Level4 and Oscillation CE scores when we 
examined the pretest and posttest balance values of the control group $(\mathrm{p}<0.05)$. However, although there was an improvement in Level 2 and Oscillation OE scores, no significant difference was found ( $p>0.05)$. However, when we examined the pretest and posttest balance values of the experimental group, a significant difference was found between Static, Level8, Level4, Level2, Oscillation OE, and Oscillation CE scores $(\mathrm{p}<0.05)$.

Today, sports performance is defined as the physiological, biomechanical and psychological efficiency that the athlete has shown during the activity. Achieving optimal and superior performance depends on the development of both the psychological and physiological capacities of the athlete and the appropriate acceleration of the athlete's performance to a certain level (Konter, 2003)

Parrish and Murphy (23) examined the effect of positive and negative imagination on motor performance. In their study, they divided 30 university students into 3 groups as positively imagining, negatively imagining and not imagining. Participants were asked to throw golf balls into the hole. As the result, it has been determined that the group that develops the most is the group that positively imagines, then the group that never imagines, and finally, the group that imagines negatively. Botwina and Krawczynski (2003 studied the effect of mental training on penalty shoot-outs in their study. In their study, both the mental and physical training group were more accurate than the other two groups (Botwina, \& Krawczynski, 2003). For example, in another recent study, video-assisted mental training has been shown to have a positive effect on shooting skills on the football. According to the findings of the research, mental training practice combined with physical training is more effective than only physical or mental training practice (Özdal et al., 2013). Martin and Hall (1995) reported in their research that the athletes making imaginative studies set higher goals and more realistic expectations than others (Martin \& Hall, 1995). As it can be seen, imagination, especially in sports, training or pre-competition, which requires a more complex and systematic presentation of motor skills, ensures that the motor skills are reinforced more positively.

As the result, the determination of the cognitive learning levels of the athletes and the development of the imagination levels as well as the physical training are necessary both for motivating themselves and for increasing their success levels. When the findings of the study are evaluated in general, it is seen that there is a significant relationship between cognitive imagination and balance skills.

\section{Suggestions}

1. Athletes should perform physical training and cognitive training and imagination exercises.

2. In basic skill teaching, the cognitive training should be emphasized so that the student/athlete can recognize himself/herself.

3. In the sport branch to be taught, the cognitive process must be initiated before physical practice and this process should be supported by imagination exercises.

4. According to the results obtained, cognitive training process and imagination training process should be applied in all sports branches with physical training.

\section{References}

Aktepe, K. (2006). The Importance of Sport Mental Training and the Determination of the Level of Interest and Practice of Mental Training of Individual National Sportsmen. Niğde University Social Sciences Institute. Master Thesis, 11-15.

Altay, F. (2001). Biomechanical Analysis of Side - Balance Motion After Two Different Speeds of Chaine Rotation in Rhythmic Gymnastics. Hacettepe University Health Sciences Institute PhD Thesis, Ankara.

Altıntaş, A., \& Akalan, C. (2008). Mental Training and High Performance, Sportmeter, 6(1), 39-43.

Ataman, A. (2004). Development and Learning, (2nd Edition). Daytime Education and Publishing Ankara, 278-322.

Botwina, R., \& Krawczynski, M. (2003). Appilication of Visitation in Training of Young Football Players 11,. European Congress of Sport Psychology, 145.

Erden, M. (1998). Social Studies Education, Ankara, Alkım Publications.

Erkmen, N., Suveren, S., Göktepe, A. S., \& Yazıcıoğlu, K. (2007). Comparison of Balance Performances of Sportsmen in Different Branches, Spormeter, 3, 115-122.

Günay, M., \& Cicioglu, İ. (2001). Sports Physiology. Ankara, Gazi Book House, 103-105.

Hazar, F., \& Taşmektepligil, M. Y. (2008). Examination of the effects of balance and flexibility on agility in the pre-puberty period. Spormeter Physical Education and Sport Sciences Journal, 5(1), 9-12.

Ikizler, C. (1997). Sporda Achievement Psychology, Alpha Publishing Distribution. 
Karagözoğlu, C. (2005). Psychological on Sport Support, Morpa Culture Publications, Istanbul.

Konter, E. (1999). Mental Training in Applied Sport Psychology, Nobel Publication Distribution, Ankara, 6-57,

Konter, E. (2003). Misconceptions and Facts in the Practice of Sports Psychology, Dokuz Eylül Publications, Ankara, 7(31), 32-37.

Konter, E. (2006). Mental Training in Applied Sport Psychology, (1st Edition). Bullish Publications, 49-155.

Mahoney, M., \& Suinn, R. M. (1986). History and Overview of Modern Sport Psychology, The Clinical Psychologist, 39(3), 64-68.

Martin, K. A., \& Hall, C. R. (1995). Using Mental Imagery To Enhance Intrinsic Motivation. J Sport Exerc Psychol, 17(1), 54-69. https://doi.org/10.1123/jsep.17.1.54

May, J. R. (1986). Sport Psychology: Should Psychologists Become Involved, The Clinical Psychologist, 39(3), 77-81.

Nichols, D. S., Glenn, T. M., \& Hutchinson, K. J. (1995). Changesi in The Mean Center of Balance During Balance Testing in Young Adults, Phys Ther., 75(8), 699-706. https://doi.org/10.1093/ptj/75.8.699

Özdal, M., Akcan, F., \& Abakay, U. (2013). The Influence of Video Assisted Mental Training Program on Future-Shooting Ability. Journal of Sports and Perfor- mans Research, 4(2), 40-46.

Özden, Y. (2004). New Values in Education, (9th Edition). Pegem Publishing, Ankara, 22-63.

Sosovec, L. G. (2004). Internal Visual Imagery and ITS Effect on Penalty Kicks in Soccer, Master Thesis, South Dakota State University.

Syer, J., \& Connolly, C. (1998). Mental Training Guide for Athletes, Pubic Publishing House, Ankara 47-56.

Tamer, K. (2000). Measuring and Evaluating Physical-Physiological Performance of Sport, Pub. Publishing House, Ankara, 130, 131-140.

Zorba, E., \& Ziyagil, M. A. (1995). Body Composition and Measurement Methods, Gen Printing, Trabzon, 184, 252-293.

\section{Copyrights}

Copyright for this article is retained by the author(s), with first publication rights granted to the journal.

This is an open-access article distributed under the terms and conditions of the Creative Commons Attribution license which permits unrestricted use, distribution, and reproduction in any medium, provided the original work is properly cited. 